\title{
Bioinspired cementitious-polymer composite for increased energy absorption
}

\author{
T. Trevor Painter ${ }^{1}$, Emily $\mathrm{Schwab}^{2}$, Nicole MacCrate ${ }^{2}$, Alexander S. Brand ${ }^{1 *}$, and Eric \\ Jacques $^{1}$ \\ ${ }^{1}$ Charles E. Via, Jr. Department of Civil and Environmental Engineering, Virginia Polytechnic \\ Institute and State University, Blacksburg, Virginia, USA 24061 \\ ${ }^{2}$ Department of Materials Science and Engineering, Virginia Polytechnic Institute and State \\ University, Blacksburg, Virginia, USA 24061
}

\begin{abstract}
Preliminary results are presented on the energy absorbing characteristics of a cementitious-polymer architecture bioinspired by the organic-inorganic composite structure of nacre. The proposed bioinspired architecture consists of an open cell, platelet-shaped 3D-printed thermoplastic lattice filled with high performance cementitious paste. The hypothesis is that, similar to nacre, the platelet arrangement and differences in mechanical properties of the thermoplastic lattice and cementitious platelets would result in increased energy absorption. Initial laboratory scale investigations were performed using notched beam samples subjected to static three-point bending. Stereo-digital image correlation was used to track global strain displacement field and Hillerborg's method was used to estimate the total fracture energy. The results indicate that this "brick-andmortar" hierarchy can increase the energy absorbing capacity of the composite by upwards of $2490 \%$ compared with the benchmark cementitious specimen. The load-deformation behaviour and total fracture energy of the bioinspired composite were found to be influenced by the platelet arrangement and size and the lattice thickness.
\end{abstract}

\section{Introduction}

The data in the literature indicates an increasing trend in the damage caused by natural disasters [1], which imposes the need for more resilient civil infrastructure [2,3]. Energy absorbing composites are effective in these scenarios to dissipate energy under static, quasistatic, dynamic, and high strain rate loading environments $[4,5]$. The challenge is to design a composite that exhibits both high strength and high toughness; conventional materials often have a trade-off of high strength with low toughness, like glass or concrete, or low strength with high toughness, like rubber. One solution is to take inspiration from nature, where evolution has improved mechanical performance by functional adaptation in hierarchical architectures [6]. Indeed, bioinspired hybrid materials have proven to demonstrate both high strength and high toughness [7]. For instance, bone and seashells are composed of relatively

\footnotetext{
* Corresponding author: asbrand@vt.edu
} 
weak components, but the hierarchical architecture of their microstructure offers significantly greater stiffness, strength, and toughness [8].

Nacre, found in certain seashells, has a "brick-and-mortar" microstructure consisting of overlapping, offset platelets of aragonite ( $\mathrm{C} \mathrm{CaCO}_{3}$ polymorph) bound by protein (Figure 1), and its volumetric composition is around $95 \%$ platelets and $5 \%$ protein [9]. The aragonite platelets have a hexagonal-like shape with a $5 \mu \mathrm{m}$ to $8 \mu \mathrm{m}$ diameter and a thickness of 200 $\mathrm{nm}$ to $900 \mathrm{~nm}$, and the protein layer is around $10 \mathrm{~nm}$ to $50 \mathrm{~nm}$ thick [9]. In this configuration, nacre exhibits toughness that is significantly greater than either individual component. A review of the literature revealed that the total fracture energy and the critical Mode I fracture toughness of nacre can be up to 2000 to 3000 times greater and 20 to 40 times greater, respectively, than monolithic $\mathrm{CaCO}_{3}[9,10]$. The unique hierarchical structure allows nacre to endure significant plastic deformation before failure and exhibit strain hardening behavior, thereby providing the microstructure of nacre to dissipate local stresses while simultaneously allowing for ductile behavior without significant losses in strength [9,11].

Most research of nacreous bioinspired materials has considered the nano- or microstructural aspects of biomimicry with few studies scaling to centimeters and larger [12-16]. For civil and structural applications in industry, the energy absorption and dissipation benefits of nacreous design would need to be scaled up to an order of meters. The objective of this study was to therefore develop a novel laboratory-scale composite having a relatively large characteristic cell size based on the structure of nacre.

\section{Experimental methodology}

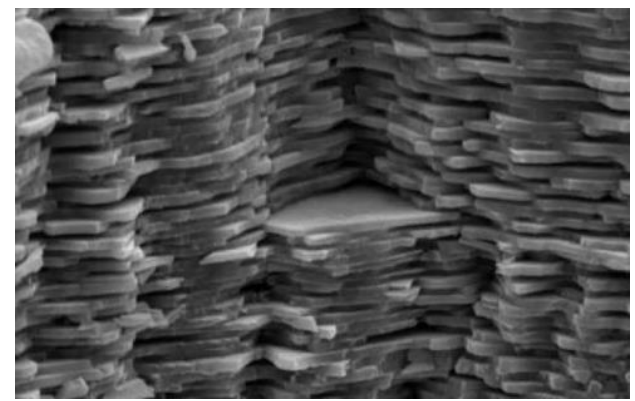

Fig 1. "Brick-and-mortar" structure of nacre. Credit: F. Heinemann (available in the public domain through Wikimedia Commons).

To mimic the "brick-and-mortar" structure of nacre, high performance cementitious paste was used as the "brick" with a 3D-printed thermoplastic lattice as the "mortar." The cementitious paste consisted of an ASTM C150 Type I/II portland cement with 10\% ASTM $\mathrm{C} 1240$ silica fume by weight. The water-to-cementitious ratio was 0.3 . A polycarboxylatebased ASTM C494 Type F high-range water reducer was also added to increase the flowability of the cementitious paste. After 14 days of curing, the paste had an average compressive strength of 9630 psi with a standard deviation of 940 psi by ASTM C109.

The thermoplastic lattice was 3D-printed using a commercial polylactic acid (PLA) filament. Figure 2 shows an example of one of the 3D-printed PLA moulds prior to casting the cementitious paste. The bioinspired plastic moulds had a 3 -inch $(7.6 \mathrm{~cm})$ square crosssection and were 8 inches $(20.3 \mathrm{~cm})$ long. A 0.1 -inch $(2.5 \mathrm{~mm})$ wide and 0.25 -inch $(6.4 \mathrm{~mm})$ tall notch was printed at midspan of the beams to compute the crack mouth opening displacement. The thickness of the outer plastic shell was 0.25 inches $(6.4 \mathrm{~mm})$ and the thickness at the bottom of the shell increased to 0.5 inches $(12.7 \mathrm{~mm})$ to accommodate the notch. Replicate beams were constructed with 3 or 5 rows of "bricks." The width of each "brick" was changed such that the 3-row design had either 10 or 16 "bricks" and the 5-row design had either 17 or 22 "bricks." The thickness of the plastic between the "bricks" was either 0.1 or 0.25 inches ( 2.5 or $6.4 \mathrm{~mm}$ ).

The nomenclature for describing the mould designs in this study is [Rows]R-[Bricks]B[Thickness]T, which represents the number of rows of "bricks" ( 3 or 5 ), the number of "bricks" $(10,16,17$, or 22), and the thickness of the plastic between the "bricks" in inches $(0.1$ or 0.25$)$. For example, the naming convention for the mould in Figure 2 is $5 \mathrm{R}-22 \mathrm{~B}-0.1 \mathrm{~T}$. 
Control moulds were also constructed with the same exterior plastic thickness but without any "brick" lattice. Finally, the designs also considered the location the "bricks" relative to the notch; some specimens had a "brick" centred directly above the notch while other specimens had polymer "mortar" above the notch.

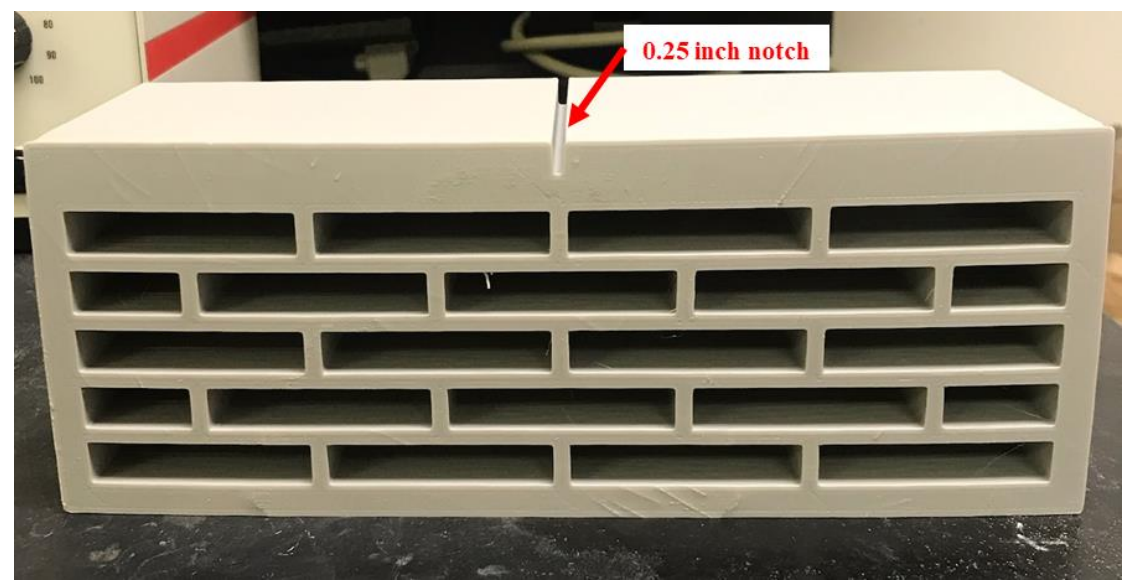

Fig 2. Example of one of the 3D-printed plastic moulds with 5 rows and 22 "bricks."

To construct the composite beams, the cementitious paste was mixed according to ASTM $\mathrm{C} 305$. The plastic mould was affixed to a steel plate using petroleum jelly to prevent the cementitious paste or water from leaking, and then the mould "bricks" were filled with cementitious paste. The paste was rodded during placement to ensure suitable filling of the mould. Once the top surface was trowelled flat, the beam was covered with plastic to prevent moisture loss. All specimens were then cured in a sealed condition for 14 days until testing. Sealed curing was selected instead of moist curing to prevent any additional moisture ingress between the hardened paste and plastic lattice.

After 14 days of curing, the front face of the beams was spray-painted white and then sprayed over with a black speckle pattern (Figure 3). By observing the time-dependent deformation of the speckles during testing by comparing digital images, stereo-digital image correlation (DIC) can be used to compute local strains and deformations relative to a reference [17]. In this study, DIC was used during the three-point bending tests to assess if the localized cracking pattern could be tracked and to compute the crack mouth opening displacement (CMOD) of the beam during deformation. The three-point bending tests with a 6-inch $(15.2 \mathrm{~cm})$ clear span were performed at a constant crosshead displacement of 1 $\mathrm{mm} / \mathrm{min}$. From the DIC data, the time-dependent CMOD was determined, and the total fracture energy $\left(\mathrm{G}_{\mathrm{F}}\right)$ was calculated based on Hillerborg's method [18], although the beam self-weight was not accounted for.

This study employed a GOM ARAMIS DIC system. Images were collected at a frequency of one per second. The DIC system consisted of a pair of 12 megapixel CMOS sensors on an $800 \mathrm{~mm}$ adjustable base. The calibration was completed with a CP40/170 calibration object with a field of view of $(320 \mathrm{~mm}, 240 \mathrm{~mm}, 240 \mathrm{~mm})$. The calibration deviation was 0.027 pixels [19], which is less than the acceptance criterion of $<0.07$ pixels. The equivalent size of a pixel in the field of view was $78.125 \mu \mathrm{m}$. When a strain sensitivity analysis was conducted on a series of reference photos, the max deviation observed was $916 \mu \mathrm{m} / \mathrm{m}$ and the average was $16 \mu \mathrm{m} / \mathrm{m}[19]$. 

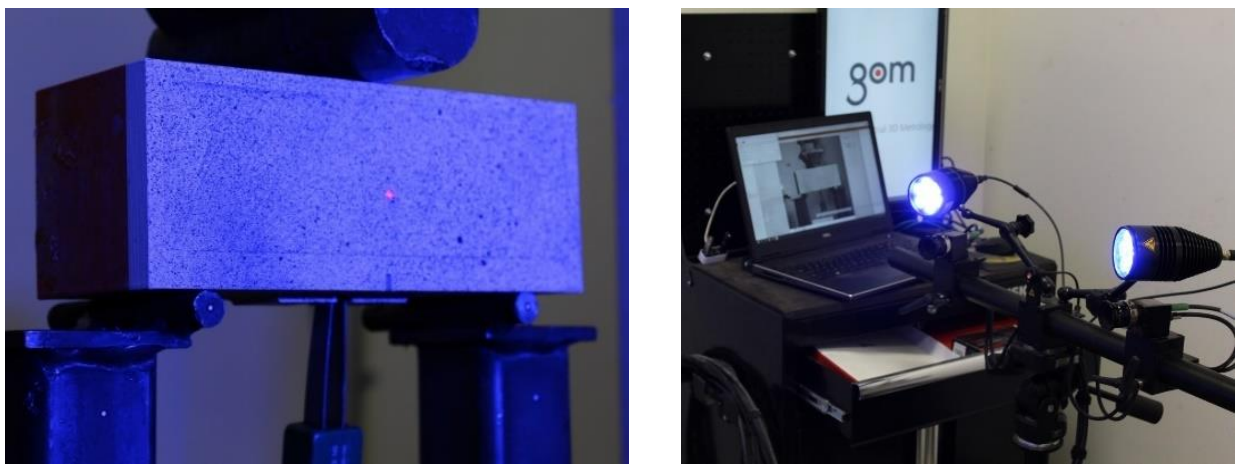

Fig 3. Control sample configured for three-point bending (left) and DIC setup (right).

\section{Results and discussion}

Table 1 includes a summary of all test results, including replicates. Note that not all specimens were considered to have failed at the end of the test. The specimen was considered to have failed if the $\operatorname{crack}(\mathrm{s})$ propagated the full specimen height (e.g., Figure 4 top), but some tests had to be stopped after significant deformation to prevent potential damage certain instrument components near the machine limit. Figure 4 shows an example of a failed control specimen and a 5-row specimen that did not completely fail by the end of the test. Figure 5 shows the load vs. CMOD results for all specimens, which, in general, agrees with the summary data in Table 1 that the nacre-inspired specimens tended to have significantly greater deformation at the end of the test relative to the control specimens.

Table 1. Peak Load and CMOD Summary Data

\begin{tabular}{lcccc}
\hline Specimen & $\begin{array}{c}\text { Peak } \\
\text { Load }(\mathbf{N})\end{array}$ & $\begin{array}{c}\text { CMOD at Peak } \\
\text { Load (mm) }\end{array}$ & $\begin{array}{c}\text { CMOD at } \\
\text { Failure }(\mathbf{m m})\end{array}$ & $\begin{array}{c}\text { Did Specimen } \\
\text { Fail? }\end{array}$ \\
\hline Control 1 & 3,411 & 2.48 & 2.48 & Yes \\
Control 2 & 5,737 & 2.82 & 2.96 & Yes \\
Control 3 & 11,164 & 1.56 & 1.82 & Yes \\
Control 4 & 3,088 & 1.28 & 1.28 & Yes \\
\hline 3R-10B-0.1T & 10,439 & 4.64 & 9.43 & No \\
3R-10B-0.25T & 7,456 & 6.52 & 6.98 & Yes \\
3R-16B-0.25T & 7,746 & 3.79 & 6.18 & Yes \\
\hline 5R-17B-0.1T (1) & 12,317 & 2.91 & 6.95 & No \\
5R-17B-0.1T (2) & 13,465 & 3.82 & 12.11 & No \\
5R-17B-0.25T (1) & 6,223 & 3.61 & 7.84 & No \\
5R-17B-0.25T (2) & 5,797 & 1.6 & 1.63 & Yes \\
5R-22B-0.25T (1) & 5,375 & 10.05 & 10.05 & Yes \\
5R-22B-0.25T (2) & 6,112 & 3.89 & 15.15 & No \\
\hline
\end{tabular}

The total fracture energy by Hillerborg's method for each specimen is shown in Table 2 and Figure 6. Since these specimens had varied "brick" and "mortar" thicknesses, the total fracture energy was normalized by multiplication by the percent polymer within the fracture ligament above the notch. All nacreous composites exhibited greater fracture energy relative to the control, with one outlier resulting in similar fracture energy. No clear trend could be identified between the performance and the various design parameters, which suggests that further study is needed. The only generalized trend is an increase in fracture energy with 
increasing percent polymer in the fracture ligament. Considering the average results, the 3row composites had total fracture energies that ranged from $1190 \%$ to $1640 \%$ greater than the control, while the 5-row composites had total fracture energies that ranged from $690 \%$ to $2490 \%$ greater than the control.

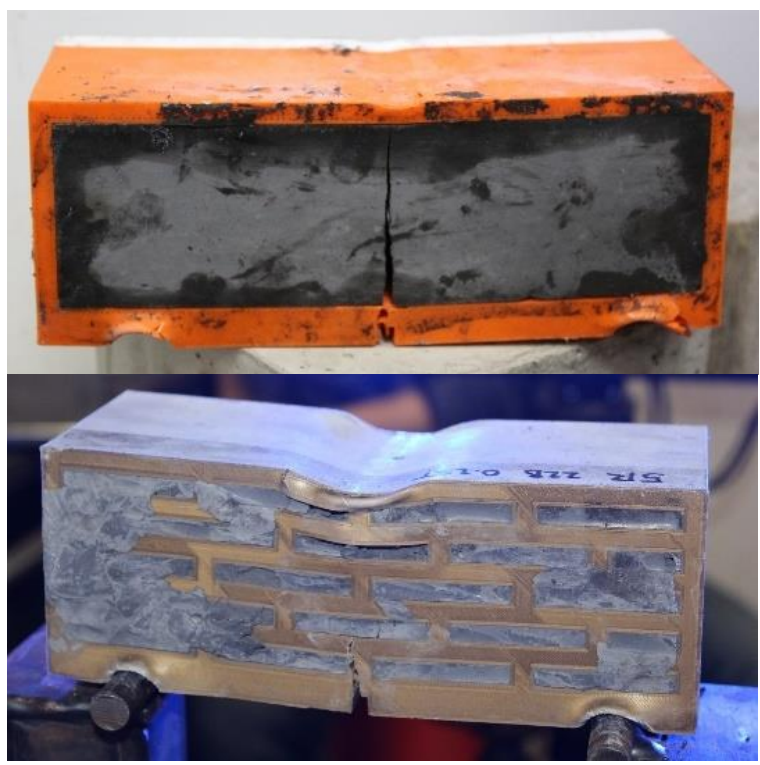

Fig 4. Specimens Control 1 (top) and 5R-22B-0.25T (2) (bottom) at the end of testing.

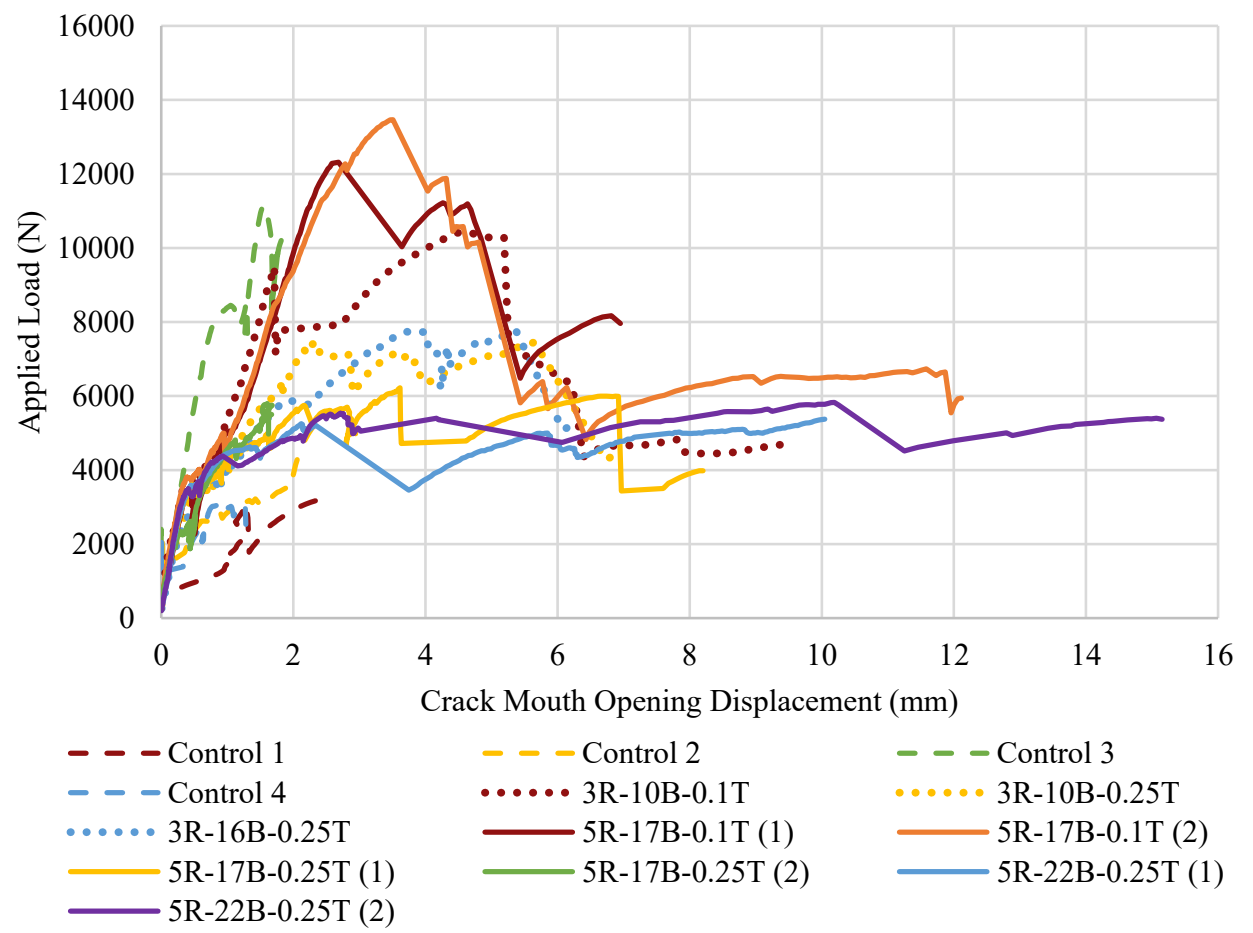

Fig 5. Applied load $v s$. CMOD for all tested specimens. 
Table 2. Fracture Energy Summary Data

\begin{tabular}{lccc}
\hline Specimen & $\begin{array}{c}\text { Fracture } \\
\text { Energy, GF } \\
\text { (N/m) }\end{array}$ & $\begin{array}{c}\text { Percent Polymer in the } \\
\text { Fracture Ligament (\%) }\end{array}$ & $\begin{array}{c}\text { Fracture Energy } \\
\text { Normalized by the } \\
\text { Percent Polymer (N/m) }\end{array}$ \\
\hline Control 1 & 913 & $25.0 \%$ & 228 \\
Control 2 & 1965 & $25.0 \%$ & 491 \\
Control 3 & 2457 & $25.0 \%$ & 614 \\
Control 4 & 556 & $25.0 \%$ & 139 \\
\hline 3R-10B-0.1T & 11751 & $54.4 \%$ & 6398 \\
3R-10B-0.25T & 7751 & $61.1 \%$ & 4736 \\
3R-16B-0.25T & 6915 & $80.6 \%$ & 5571 \\
\hline 5R-17B-0.1T (1) & 10943 & $63.0 \%$ & 6894 \\
5R-17B-0.1T (2) & 16960 & $63.0 \%$ & 10685 \\
5R-17B-0.25T (1) & 7396 & $66.7 \%$ & 4930 \\
5R-17B-0.25T (2) & 1306 & $66.7 \%$ & 871 \\
5R-22B-0.25T (1) & 8560 & $83.3 \%$ & 11952 \\
5R-22B-0.25T (2) & 14342 & $83.3 \%$ & \\
\hline
\end{tabular}

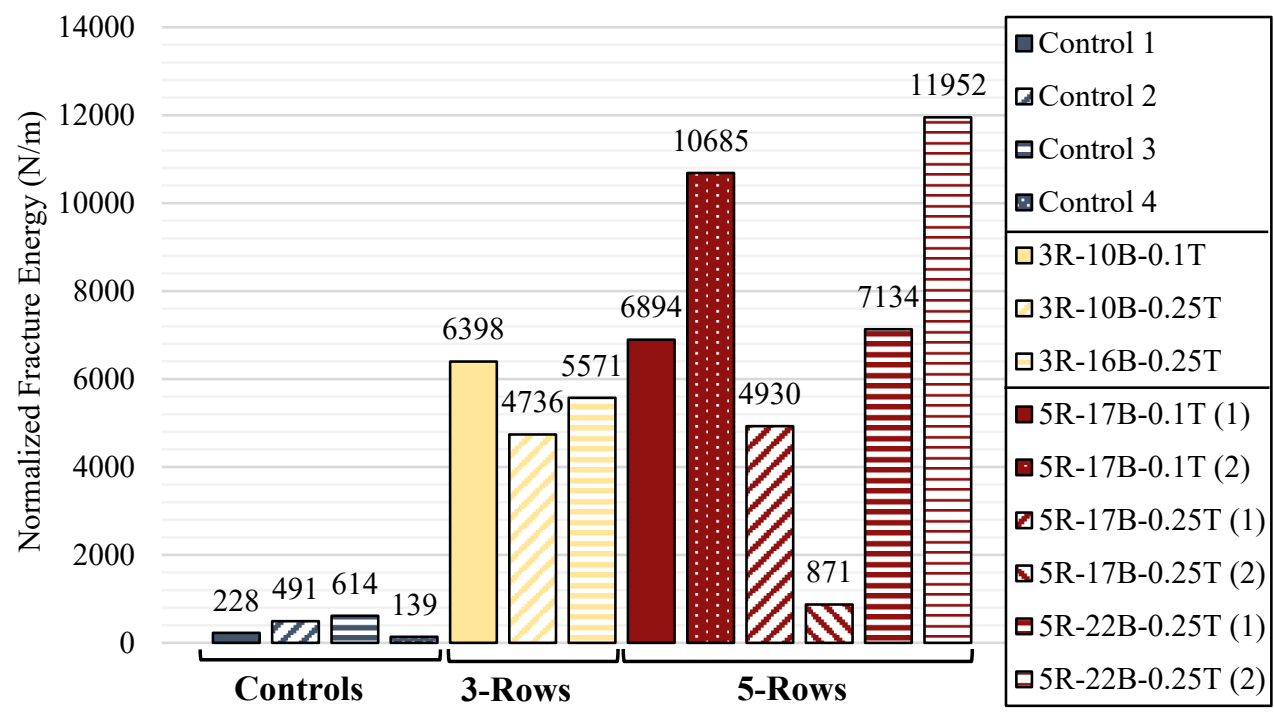

Fig 6. Total fracture energy for each specimen normalized by the percent of polymer in the ligament.

The application of DIC in this study was also beneficial to track the localized strains and deformations in the composite during cracking. Figure 7 shows the results for one of the 5row composite beams at four specific points during the test. The use of DIC was clearly able to track locations of high local strain attributable to the anisotropic nature of the composite. 


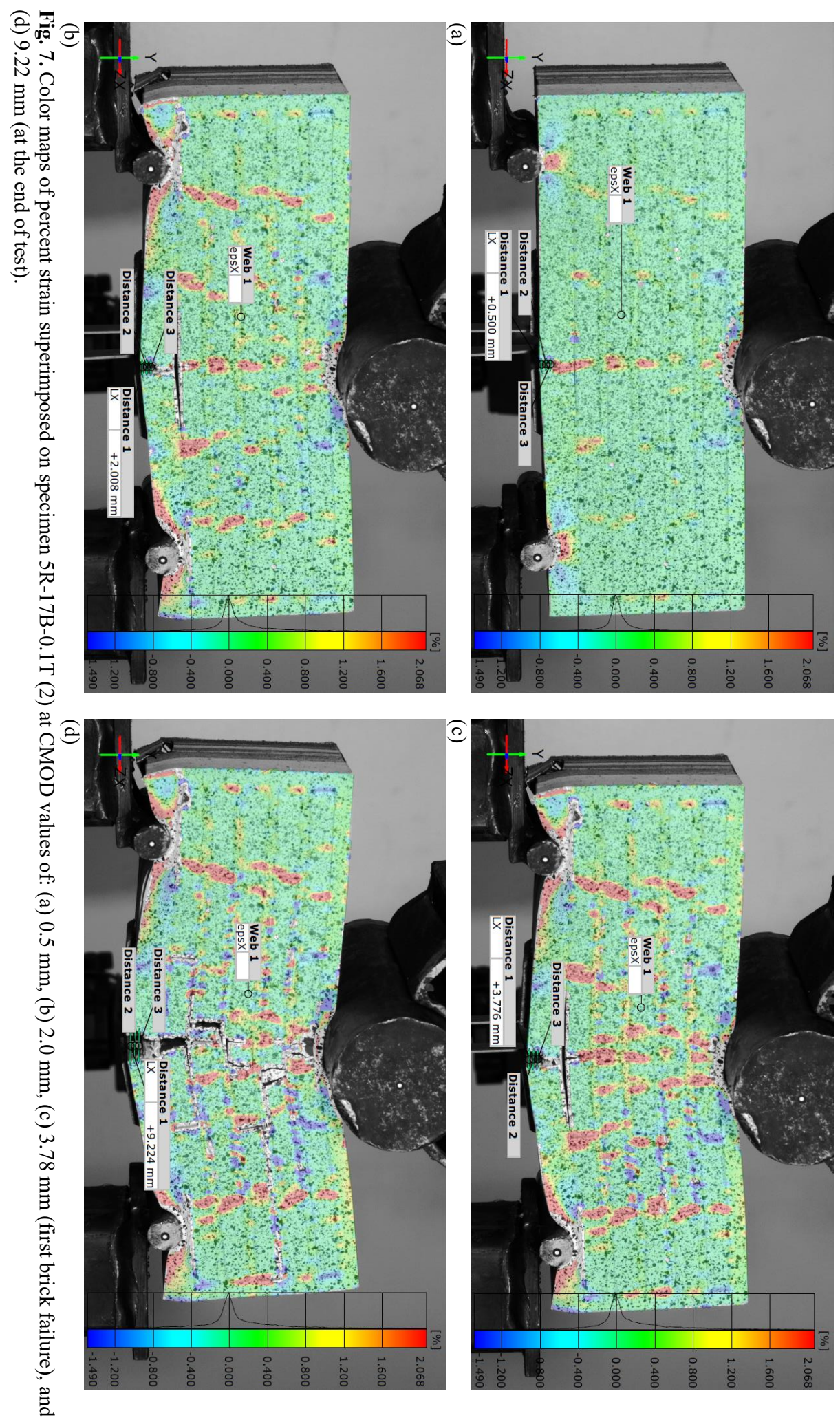




\section{Conclusions and recommendations}

A bioinspired nacreous composite was investigated for civil infrastructure application. Laboratory-scale composite beams were constructed in "brick and mortar" architecture where a 3D printed polymer shell with open cells was filled with a high strength cementitious paste. Using a three-point beam configuration and digital image correlation, it was found that the bioinspired composite exhibited greater deformation and energy absorbing capacity relative to the control. The total fracture energy was found to increase by upwards of $2490 \%$.

Given the increased deformation and the potential for increased energy absorption capacity, one potential application of this composite is for civil infrastructure designed for high strain rate or dynamic events [20-22]. The enhanced energy absorption could feasibly yield greater fatigue resistance and improved resiliency.

This pilot study clearly demonstrated the ability of a bioinspired nacreous composite beam to experience significant deformation before failure. Future work needs to further explore the effects of cementitious paste "brick" size and aspect ratio, thickness of the plastic "mortar," composition of the plastic and cementitious paste, etc. In addition, the "brick and mortar" structure is an oversimplification, as the nacre structure is better described as "brickbridge-mortar," since there are mineral "bridges" between the "bricks" that have been shown to have a crucial impact on the mechanical properties of nacreous materials [23]. Finally, the application of DIC requires further work to better refine the analysis, such analysis of the brick-mortar interfacial strains and deformations.

\section{References}

1. M. Coronese, F. Lamperti, K. Keller, F. Chiaromonte, and A. Roventini, Proc. Natl. Acad. Sci. 116, 21450 (2019).

2. J. O. Arumala, Leadersh. Manag. Eng. 12, 147 (2012).

3. K. J. Johnson, J. F. Fung, T. P. McAllister, S. L. McCabe, S. Sattar, and C. L. Segura Jr., Nat. Hazards Rev. 21, 06019002 (2020).

4. R. T. Leon and Y. Gao, Front. Struct. Civ. Eng. 10, 239 (2016).

5. F. Stochino, C. Bedon, J. Sagaseta, and D. Honfi, Adv. Civ. Eng. 2019, 4291703 (2019).

6. P. Fratzl and R. Weinkamer, Prog. Mater. Sci. 52, 1263 (2007).

7. R. O. Ritchie, Nat. Mater. 10, 817 (2011).

8. F. Barthelat and R. Rabiei, J. Mech. Phys. Solids 59, 829 (2011).

9. U. G. K. Wegst, H. Bai, E. Saiz, A. P. Tomsia, and R. O. Ritchie, Nat. Mater. 14, 23 (2015).

10. M. A. Meyers, P.-Y. Chen, A. Y.-M. Lin, and Y. Seki, Prog. Mater. Sci. 53, 1 (2008).

11. F. Barthelat, H. Tang, P. D. Zavattieri, C.-M. Li, and H. D. Espinosa, J. Mech. Behav. Biomed. Mater. 55, 306 (2007).

12. G. Mayer, Mater. Sci. Eng. C 26, 1261 (2006).

13. J. Sun and B. Bhushan, RSC Adv. 2, 7617 (2012).

14. I. Corni, T. J. Harvey, J. A. Wharton, K. R. Stokes, F. C. Walsh, and R. J. K. Wood, Bioinspiration and Biomimetics 7, 031001 (2012).

15. H. Zhao, Z. Yang, and L. Guo, NPG Asia Mater. 10, 1 (2018).

16. D. G. Soltan, R. Ranade, and V. C. Li, in 13th Int. Symp. Multiscale, Multifunct. Funct. Graded Mater. (Blucher, São Paulo, 2014).

17. M. A. Sutton, J.-J. Orteu, and H. W. Schreier, Image Correlation for Shape, Motion and Deformation Measurements (Springer, Boston, 2009).

18. A. Hillerborg, Mater. Struct. 18, 291 (1985). 
19. M. C. Jenkins, A. S. Brand, T. T. Painter, and S. T. Sherry, in 6th Int. Conf. Civil, Struct. Transp. Eng. (2021), pp. 146 1-8.

20. M. Yang and P. Qiao, in Blast Prot. Civ. Infrastructures Veh. Using Compos., edited by N. Uddin (Woodhead Publishing, Oxford, 2010), pp. 88-119.

21. G. Lu and T. Yu, Energy Absorption of Structures and Materials (Woodhead Publishing, Cambridge, 2003).

22. H. Bornstein and K. Ackland, WIT Trans. Eng. Sci. 77, 125 (2013).

23. G. X. Gu, F. Libonati, S. D. Wettermark, and M. J. Buehler, J. Mech. Behav. Biomed. Mater. 76, 135 (2017). 